УДК 622. 322

\title{
МЕХАНИЗМ ФИЛЬТРАЦИИ ПЛАСТОВОЙ ЖИДКОСТИ В ФИЛЬТРЕ, НАХОДЯЩЕМСЯ В КОНТАКТЕ С ГОРНОЙ ПОРОДОЙ
}

\author{
Хабибуллин Марат Яхиевич, \\ m-hab@mail.ru
}

Уфимский государственный нефртяной технический университет, филиал в г. Октябрьский, Россия, 452607, г. Октябрьский, ул. Девонская, 54-а.

\begin{abstract}
Актуальность исследования обусловлена необходимостью предотвратить введение в прифильтровую зону объема породы с больщей однородностью и больщего размера по сравнению с крупной фракцией пластового песка - попытка добиться

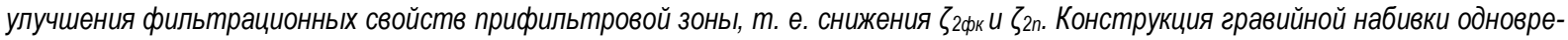
менно должна исключать вынос частиц пласта в скважину. Решение этой проблемы позволит улучшить работу филььтрации пластовой жидкости из пласта в скважину и сократить затраты на дополнительное применение методов интенсификации притока пластовой жидкости к скважине.

Цель: разработать методику, позволяющую при выборе конструкции фильтра, одновременно с возможностью обеспечения им надежной гидравлической связи в системе пласт-фильтр, предотвращать вынос песка в скважину.

Объекты. Для предотвращения поступления песка из пласта и удержания гравия на забое скважины при создании гравийных набивок применяют щелевые, проволочные, кольцевые, титановые, металлокерамические и другие фильтры. Эти фильтры, установленные в интервале перфорации обсадной колонны без образования гравийной наружной кольцевой набивки (а именно таким образом в большинстве скважин устанавливаются фильтры на месторождениях России), очень часто забиваются пластовым песком, что приводит к снижению продуктивности скважин. Если для задержания песка используются щелевые фильтры, то эфффективность их применения зависит от соответствия размера щелей гранулометрическому составу выносимого песка. Фильтры с ракушечной набивкой более эфрфективны, но также не всегда отвечают поставленной цели, поскольку прочность и качество ракушечника, закачиваемого в прискважинную часть пласта, довольно низкие. Кроме того, примененные на промыслах проволочные фрильтры не имеют фриксации каждого витка, в результате чего при механическом повреждении одного из витков происходит срыв всей намотки.

Методы. При применении предложенной методики полученные результаты экспериментальных работ по оценке способов снижения выноса песка из несиементированных неоднородных пластов показывают, что применение фильтров в обсаженном стволе требует создания гравийной набивки в кольцевом зазоре между фильтром и колонной, в перфорированном канале и за обсадной колонной. Причем размер гравия должен быть выбран таким, чтобы исключить перемешивание гравийной обсыпки с пластовым песком за счет миграции и интрузии песка, $m$. e. $D / d=4-5$. Снижения производительности скважин можно в этом случае избежать путем увеличения размера и количества перфорационных отверстий. Следует отметить, что предотвращение выноса песка означает, что при оптимальном установившемся режиме работы скважины фрильтр удерживает частицы скелета пласта, но пропускает мелкодисперсные и глинистые частицы. В период запуска скважины картина несколько иная - пропускается и часть скелетообразующих частиц до того момента, пока на фильтрующей оболочке не образуется естественный фолььтр из отсортированных крупных фрракций.

Результаты. Частицы, которые составляют структуру породы, не должны выносится из пласта за счет применения фильтра. Практически это означает, что фильтр должен не пропускать 75-85 \% (по весу) более крупных фрракций песка. Для сохранения общей устойчивости скелета пласта можно допустить вынос мелких частиц не более 15-25 \% (во весу).
\end{abstract}

\section{Ключевые слова:}

Песчаник, прискважинный, скважина, термический, методы, интенсивный.

\section{Введение}

В последнее время в связи с развитием и внедрением термических методов повышения нефтеотдачи пластов проблема борьбы с пескопроявлениями в скважинах стала особо актуальна. В результате выноса песка из пласта значительно снижается эффективность применения термических методов [1]. Так, например, из-за интенсивного разрушения прискважинной части пласта и образования песчаных пробок в нагнетательных и эксплуатационных скважинах паротепловое воздействие на нефтяные пласты Малгобек-Вознесенского месторождения признано неэффективным [2].

\section{Методология}

Наиболее перспективным методами борьбы с этими пескопроявлениями являются технологии и оборудование, которые позволяют задерживать песок в затрубном пространстве:
- закачка в затрубное пространство призабойной зоны скважины цементных, пеноцементных и цементно-песчанных смесей;

- применение на забое фильтров различных конструкций;

- нагнетание в призабойную зону скважин песка с крупной фракцией зерен и гравия;

- закачка в затрубное пространство призабойной зоны скважины синтетических смол;

- комбинированные способы, включающие вышеперечисленные.

Для предотвращения поступления песка из пласта и удержания гравия на забое скважины при создании гравийных набивок применяют щелевые, проволочные, кольцевые, титановые, металлокерамические и другие фильтры [3]. Эти фильтры, установленные в интервале перфорации обсадной колонны без образования гравийной наружной кольцевой набивки 
(а именно таким образом в большинстве скважин устанавливаются фильтры на месторождениях России), очень часто забиваются пластовым песком, что приводит к снижению продуктивности скважин [4]. Если для задержания песка используются щелевые фильтры, то эффективность их применения зависит от соответствия размера щелей гранулометрическому составу выносимого песка. Однако даже при тщательном подборе фильтра наблюдается снижение продуктивности скважин из-за его кольматации [5]. При эксплуатации скважин в условиях применения тепловых методов повышения нефтеотдачи эти фильтры также не обеспечивают надежную защиту от поступления песка в скважину. Так, на месторождении Кенкияк, где осуществлялось паротепловое воздействие, проволочные фильтры были установлены в 255 скважинах. В 177 из них была получена низкая эффективность защиты от поступления песка в скважину [6]. Основными недостатками проволочных фильтров является то, что при их использовании без гравийной набивки мелкие частицы глины и песка поступают из пласта в скважину, образуя между фильтром и обсадной колонной уплотненный слой песка с низкой проницаемостью.

Фильтры с ракушечной набивкой более эффективны, но также не всегда отвечают поставленной цели, поскольку прочность и качество ракушечника, закачиваемого в прискважинную часть пласта, довольно низкие [7]. Кроме того, примененные на промыслах проволочные фильтры не имеют фиксации каждого витка, в результате чего при механическом повреждении одного из витков происходит срыв всей намотки.

В последнее время в НПО «Союзтермнефть» было предложено несколько новых конструкций фильтров, среди которых особого внимания заслуживает металлокерамический фильтр с титановыми фильтрующими элементами. Титановые фильтрующие элементы обладают высокой проницаемостью (не менее 3 мкм²) $^{2}$ с размером пор 150-200 мкм и пределом прочности на смятие не менее 1,5 МПа [8]. Несмотря на бесспорные достоинства титановых фильтроэлементов (коррозионная и термическая стойкость, биологическая инертность, возможность многократного использования), они обладают рядом недостатков, сдерживающих их широкое внедрение. Так, если песчаный пласт содержит глинистый материал, то наблюдается быстрая кольматация фильтров при эксплуатации скважин, фильтры разрушаются уже при репрессии $0,9 \ldots 1,2$ МПа при их обратной промывке, при спуске фильтров на забой скважины происходит разрушение титановых фильтроэлементов.

Одним из наиболее эффективных способов предотвращения поступления песка в скважину является создание за обсадной колонной в прискважинной части пласта гравийной набивки [9]. Гравийные набивки используются на месторождениях как с чисто песчаными (с широким фракционным составом), так и с глинисто-песчаными коллекторами. Однако опыт создания набивок показал, что при неполном намыве гравия и при неплавном пуске скважины в эксплуатацию (сразу на полную подачу) происходит вынос песка в скважину, причем межремонтный период не превышает 8-15 суток [10].

С течением времени наблюдается проседание гравия из-за переуплотнения набивки, приводящее к образованию полостей, свободных от гравия, через которые песок вновь начинает поступать в скважину. Наиболее широко используемый материал для гравийной набивки - природный крупнозернистый песок. Однако применение такого наполнителя в значительной степени ограничено из-за растворения кремнезема горячими высокощелочными жидкостями [11] (особенно при закачке в пласт водяного пара), а также дробления песка при намыве набивки. Использование других материалов в качестве наполнителя для набивки широкого применения не получило. Широкое внедрение метода создания гравийных набивок сдерживается недостатком оборудования для проведения процесса (оно в основном импортное - фирмы «Lynes» и «BIWIncorporated») [12]. Кроме того, данный метод имеет малую эффективность для условий месторождений, разрабатываемых с осуществлением термических методов повышения нефтеотдачи.

\section{Обсуждение}

Среди методов и способов крепления прискважинной части пласта наибольшее распространение на практике получили такие, как консолидация слабосцементированных песчаников цементными растворами, смолами и тампонирующими составами на их основе. Результаты испытаний способов крепления прискважинной части пласта цементными растворами показали, что наряду с осложнениями, возникающими при закачке раствора в пласт (выпадение песка из раствора, образование цементной пробки на забое скважины), наблюдается непродолжительность эффекта, значительное снижение проницаемости закрепленной зоны (остаточная проницаемость не пре-


цементные растворы для крепления прискважинной части пласта используются редко. Чаще всего крепление слабосцементированных коллекторов осуществляется фенольными, фенолформальдегидными, фурановыми и фенолофурановыми смолами. При этом достигаются высокие значения предела прочности консолидированной породы на сжатие (до 10-20 МПа). Одним из основных параметров, характеризующих эффективность процесса крепления слабосцементированных коллекторов, является остаточная проницаемость закрепленной зоны. В литературных источниках приводятся противоречивые данные по этому вопросу. В работе [13] авторы утверждают, что при креплении чистого высокопроницаемого песка фрак-

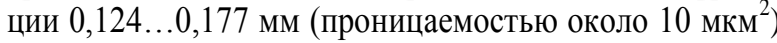
достигается остаточная проницаемость порядка 50$90 \%$ от первоначальной, в то время как по другим данным не более 10-30 \%. Крепление прискважинной части пласта смолами рекомендуется при следующем сочетании пластовых условий [14]:

- небольшая мощность обрабатываемого пласта (не более $3 \mathrm{M}$ ); 
- высокое пластовое давление;

- однородный по проницаемости закрепляемый участок пласта;

- тенденция к увеличению выноса песка в процессе эксплуатации.

При креплении скважин водорастворимыми смолами ТСД-9, ТС-10, СФЖ-3012 отмечено, что эффективность обработки зависит от содержания воды в добываемой продукции. При креплении скважин Анастасиевско-Троицкого месторождения водорастворимыми смолами при добыче безводной продукции наблюдалось прекращение выноса песка из пласта до года и более. В условиях, когда на забое добывающих скважин появлялась вода, эффективность резко снижалась. При этом наблюдались такие осложнения, как вынос песка и затвердевшей смолы, затрудненное освоение скважин. Эксперименты показали, что при прочих равных условиях наличие воды в образце снижает прочность в 1,5 раза в сравнении с нефтенасыщенными образцами. Для крепления обводнившихся скважин используются смолопесчаные смеси, приготовленные на поверхности и закачиваемые в прискважинную часть пласта. Опыт применения синтетических смол показал, что при наличии кавернозности в прискважинной части устранить вынос песка не всегда удается. В этом случае затвердевание смолы в каверне приводит к снижению продуктивности скважины. Кроме того, за счет гравитационных сил смола размещается в нижней части пласта, не укрепляя верхнюю. Для крепления кавернозных прифильтровых зон используются вспененные смолы. Однако при этом прочность закрепленной зоны не превышает 3,0 МПа. Кроме того, способ не применим в скважинах с забойными температурами свыше 383 К. Кроме указанных способов крепления слабосцементированных коллекторов применяются и комбинированные методы, такие как укрепление гравийной набивки смолами [15]. В последнее время зарубежными фирмами было предложено большое количество новых составов смол: «Аква-Эпон» фирмы «Shell», «Сендлокк 5» фирмы «Dowell», «Сен-СтопАква» фирмы «ВIHауеs» и другие [16].

Во ВНИИКРнефть в конце 1970-х гг. был разработан проницаемый полимерный материал Контарен, приготовляемый на основе сланцевых алкилрезорцинов и уротропина. При креплении слабосцементированных коллекторов составом Контарен достигается высокая проницаемость - 2-50 мкм², предел прочности на сжатие составляет 2,5...4,5 МПа, термостойкость - до 473 К. Одним из осложнений, возникающих при использовании состава Контарен, является трудность освоения скважин, так как для притока пластовых флюидов необходимо создание фильтрационных каналов путем растворения затворенного в смоле гранулированного хлорида натрия. В табл. 1 приводятся основные характеристики синтетических смол и составов на их основе для крепления прискважинной части пласта.

Таблица 1. Характеристика смол и составов на их основе, используемых для крепления прискважинной части плаcma

Table 1. Characteristics of resins and compositions based on them used for fixing the near-wellbore portion of the formation

\begin{tabular}{|c|c|c|c|c|}
\hline $\begin{array}{l}\text { Название состава } \\
\text { Name } \\
\text { of the composition }\end{array}$ & $\begin{array}{c}\text { Рабочий температурный } \\
\text { диапазон, K } \\
\text { Working temperature } \\
\text { range, } \mathrm{K} \\
\end{array}$ & \begin{tabular}{|c|} 
Предел прочности \\
на сжатие, МПа \\
Tensile strength compression, \\
МПа \\
\end{tabular} & $\begin{array}{c}\text { Остаточная } \\
\text { проницаемость, мкм } \\
\text { Residual permeability, } \\
\text { мм }^{2} \\
\end{array}$ & \begin{tabular}{|c|} 
Пригодность для обработки \\
глинизированных песков \\
Suitability for processing \\
claysands \\
\end{tabular} \\
\hline $\begin{array}{c}\text { Бейкер Пласти } \\
\text { Baker Plasti }\end{array}$ & $311-380$ & - & - & $\begin{array}{l}\text { рекомендуется } \\
\text { recommended }\end{array}$ \\
\hline $\begin{array}{c}\text { Сент-Бонд } 4 \\
\text { St Bond } 4 \\
\end{array}$ & $311-422$ & - & - & $\begin{array}{c}\text { пригодна } \\
\text { fit } \\
\end{array}$ \\
\hline K-90 & $355-411$ & - & - & \begin{tabular}{|c|} 
пригодна до $20 \%$ глин \\
suitable for up to $20 \%$ of clays \\
\end{tabular} \\
\hline $\begin{array}{l}\text { Эпокси } 2 \\
\text { Ероху } 2 \\
\end{array}$ & $311-366$ & - & - & $\begin{array}{l}\text { пригодна } \\
\text { fit }\end{array}$ \\
\hline $\begin{array}{l}\text { Санфикс } \\
\text { Sanfix }\end{array}$ & - & $10-15$ & до 0,60 & $\begin{array}{c}\text { пригодна } \\
\text { fit }\end{array}$ \\
\hline $\begin{array}{l}\text { Инкричед Санфикс } \\
\text { Incriched Sanfix }\end{array}$ & до 450 & $3-29$ & - & $\begin{array}{c}\text { непригодна } \\
\text { unfit }\end{array}$ \\
\hline $\begin{array}{l}\text { СФЖ-3012 } \\
\text { SFZh-3012 }\end{array}$ & $293-423$ & $3,5-4,5$ & $2-50$ & 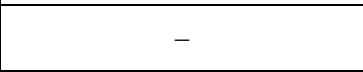 \\
\hline ССФ/SSF & $293-373$ & - & - & - \\
\hline $\begin{array}{l}\text { Контарен } \\
\text { Kontaren }\end{array}$ & до 473 & - & - & - \\
\hline
\end{tabular}

С целью снижения влияния воды на прочность закрепляемой зоны в ряде случаев предусматривается введение в пласт добавок $\left(\mathrm{FeCl}_{3}\right.$ и другие), повышающих адгезию смолы на поверхности породы. Эффективность крепления снижается, если до крепления прискважинная часть пласта была обработана плавиковой кислотой. В этом случае прочность большинства смол снижается на 50 \% и более.
Следует отметить, что ввиду сравнительно высокой стоимости смол и сопутствующих реагентов крепление прискважинной части пласта смолами и тампонажными составами на их основе стоит дороже, чем спуск фильтра или намыв гравийной набивки [16].

В последние годы у нас в стране и за рубежом проделан большой объем работ по изысканию эффективных составов на синтетической основе для креп- 
ления слабосцементированных коллекторов и разработке технологий крепления прискважинной части пласта.

Узкие границы применимости, а также довольно высокая стоимость синтетических смол сдерживает их широкое внедрение в практику нефтедобычи.

Для проектирования средств задержания песка и выявления условий разрушения материала прискважинной зоны пласта крайне важно получать пластовые керны высокого качества, т. е. относительно ненарушенные. Их следует изучать везде, где ожидаются осложнения с выносом песка и планируются большие масштабы разработки природных ресурсов.

Полученные образцы кернов подвергают испытаниям в камерах с трехосным нагружением, в результате чего строят диаграмму Мора, широко используемый критерий для изучения сдвигового разрушения грунтов, а также арочного эффекта при различной насыщенности флюидами, скоростей течения жидкости и нагружения [17], что позволяет предсказать поведение пород на различных стадиях разработки нефтенасыщенных пластов и предупредить их разрушение и вынос песка в скважины [18].

Сопротивление системы пласт-фильтр $\left(\zeta_{2}\right)$, зависящее от несовершенства по характеру вскрытия пласта, включает в себя кроме вышеуказанных гидравли- ческих характеристик фильтров гидравлические характеристики пород в прифильтровой зоне [19]. В случае скачкообразного изменения проницаемости пород в пласте

$$
\zeta_{2 n}=\left(\frac{K_{n}}{K_{u}}-1\right) \ln \frac{r_{u}}{r_{c}},
$$

где $K_{n}$ и $K_{u}$ - соответственно коэффициенты фильтрации пород продуктивного пласта и у скважины в зоне с измененной проницаемостью; $r_{u}-$ радиус зоны с измененной проницаемостью, м; $r_{c}$ - радиус фильтра, м.

Графики рассматриваемой зависимости приведены на рис. 1. Из графиков видно, что более интенсивно изменяется $\zeta_{2 n}$ при меньших отношениях $r_{u} / r_{c}$ и отношение $K_{n} / K_{u}$ в меньшей степени влияет на изменение $\left(-\zeta_{2 n}\right)$, чем на изменение $\left(+\zeta_{2 n}\right)$.

Из вышесказанного следует, что сопротивление $\zeta_{2}$, представляющее собой комплексную характеристику, зависящую от качества заканчивания скважины, гидравлических особенностей фильтра, обусловленных конструкцией, а также от уменьшения проницаемости породы в прифильтровой зоне в процессе эксплуатации, зависит главным образом от совокупности показателей $\zeta_{2 \phi к}$ и $\zeta_{2 n}$ и изменения их в процессе эксплуатации скважины [20].

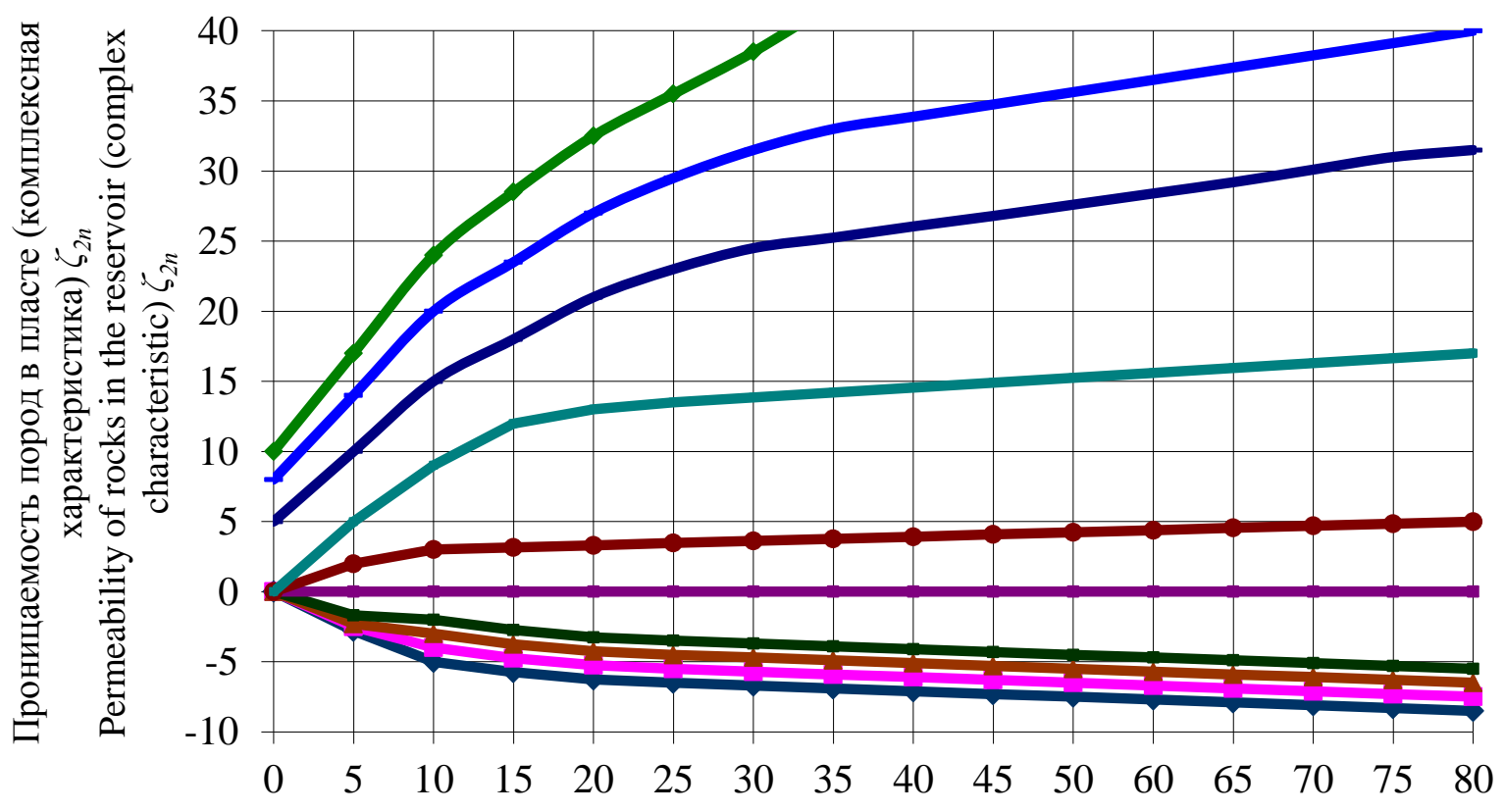

Отношение радиусов зоны с измененной проницаемостью и фильтра $r_{u} / r_{o}$ Ratio of the radii of the zone with the changed permeability and the filter $r_{u} / r_{o}$ Отношение коэффициентов фильтрации пород

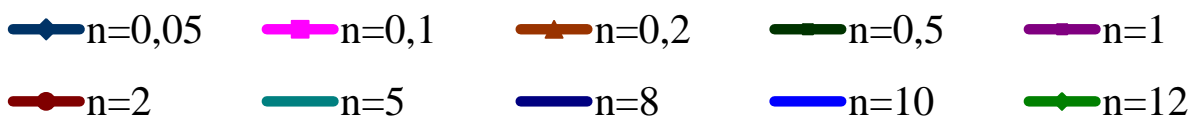

Pис 1. Зависимость проницаемости пород в пласте от отномения радиусов и коэффициентов фильтрации

Fig 1. Dependence of rock permeability in the reservoir on the ratio of radii and filtration coefficients 
Если представить гидравлическую связь пластфильтр в виде зон, на которых происходит изменение режимов фильтрации, то это будет выглядеть следующим образом: (рис. 2, a-2). Согласно этой схеме дадим и условные определения ее составляющих:

а) зона пласта, где скорость движения добываемой жидкости меньше критической скорости для выноса частиц, которые предполагается пропускать через фильтр; б) зона пласта, где скорость движения добываемой жидкости больше критической скорости для выноса частиц, которые предполагается пропускать через фильтр;

в) зона взаимодействия горной породы, которая равна толщине оболочки фильтрующего элемента;

г) металлическая конструкция фильтра, при которой обеспечивается вынос из скважины частиц, прошедших через фильтр.

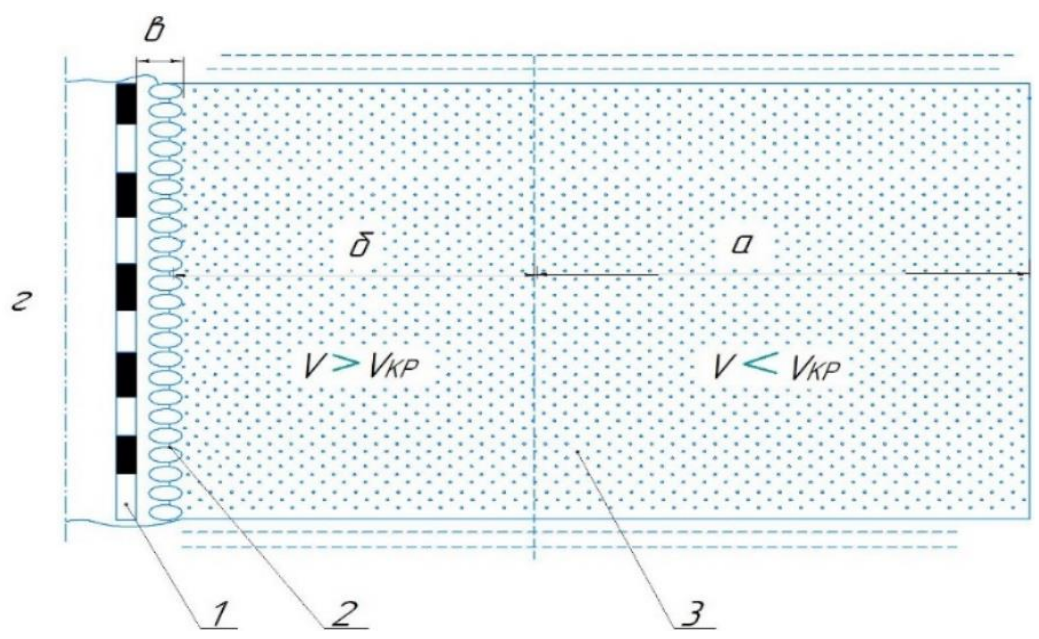

Pис. 2. Схема гидравлической связи пласт-фильтр: 1 - каркас фильтра; 2 - фильтруюшая оболочка; 3 - пласт

Fig. 2. Diagram of the reservoir-filter hydraulic connection: 1 -filter frame; 2 -filtering shell; 3 -layer

При постановке фильтров в скважину с забоем, пласт которого сложен неоднородными, слабосцементированными или рыхлыми песчаниками, зачастую со сниженной проницаемостью за счет некачественного заканчивания, следует стремиться к максимальному снижению $\zeta_{2 \phi к}$ за счет повышения скважности фильтрующей оболочки и тем самым увеличения качества фильтрационных ходов для пропуска кольматанта, что способствует и снижению $\zeta_{2 n}$.

Введение в прифильтровую зону объема породы с большей однородностью и большего размера по сравнению с крупной фракцией пластового песка попытка добиться улучшения фильтрационных свойств прифильтровой зоны, т. е. снижения $\zeta_{2 \phi к}$ и $\zeta_{2 n}$. Конструкция гравийной набивки одновременно должна исключать вынос частиц пласта в скважину.

Анализ теоретических решений и экспериментальных данных, приведенных в литературе, по обоснованию выбора соотношения размера гравия по отношению к размеру пластового песка показал, что с развитием методов эксперимента и накоплением лабораторных и промысловых данных это соотношение имеет тенденцию к уменьшению [21]. Хронологически это выглядит следующим образом.

В работе [22] при однородном составе гравийной обсыпки и пластового песка дается соотношение:

$$
D / d=10-12 \text {, }
$$

где $D$ - диаметр гравия, мм; $d$ - диаметр крупных фракций песка, мм.

В работах $[23,24]$ соотношение $D / d=8-12$, но взятое с учетом сводообразования и диаметром зерен, кото- рые предполагается удержать от выноса, а требования о недопущении проникновения песчаных частиц в фильтр, т. е. предотвращения его кольматации и без учета сводообразования, выражается соотношением $D / d=4-5$. Эффективность работы гравийного фильтра от соотношения между размером гравия и зерен пластового песка, неоднородного по гранулометрическому составу, исследовалась в работах [23, 24]; рекомендовано соотношение $D_{\max }$ (максимальный размер гравия) $/ d_{10}$ (размер зерен пластового песка, соответствующих $10 \%$ остатку при ситовом анализе) $=10$.

Исследования, проведенные в условиях, приближенных к скважинным, когда при закачке гравия происходит его смешивание с песком в призабойной зоне или в колонне при оседании песка во время обратной промывки, показывает, что это приводит к снижению проницаемости прифильтровой зоны и продуктивности скважины [25].

Эффективность применения гравийной набивки снижается и от качества ее подготовки. Кроме того, смешение гравия и песка происходит также во время эксплуатации скважины в том случае, если гравий велик и не может остановить движение песка.

Данные по изменению проницаемости смеси различного размера гравия с песком (Оклахома, пласт № 1) приведены в табл. 2 .

Данные таблицы показывают, что при определенных пропорциях смешивания гравия и песка проницаемость смеси может быть меньше проницаемости песка. В забойных условиях (при сжатии породы) смешивание приводит к еще большей потере пористости и проницаемости. Эффект от смешения песка 
и гравия значителен. Значения проницаемости сжатых смесей приведены в табл. 3, из которой видно, что проницаемость смесей песка с гравием размером $0,25 \ldots 0,42$ выше, чем у остальных.

Таблица 2. Изменение проницаемости смеси различного размера гравия с песком

Table 2. Change in permeability of a mixture of different sizes of gravel with sand

\begin{tabular}{|c|c|c|c|c|c|c|c|}
\hline $\begin{array}{c}\text { Размер гра- } \\
\text { вия, мм } \\
\text { Gravel size, } \\
\text { mm }\end{array}$ & $\begin{array}{c}\text { Содержание гра- } \\
\text { вия в смеси, \% } \\
\text { Gravel content in } \\
\text { the mixture, \% }\end{array}$ & $\begin{array}{c}\text { Проницаемость, } \\
\text { мкм }^{2} \\
\text { Permeability, } \\
\text { mcm }^{2}\end{array}$ & $\begin{array}{l}K_{\text {смеси }} \\
K_{\text {песка }} \\
K_{\text {smesi }} \\
K_{\text {peska }}\end{array}$ & $\begin{array}{c}\text { Размер гра- } \\
\text { вия, мм } \\
\text { Gravel size, } \\
\text { mm }\end{array}$ & $\begin{array}{c}\text { Содержание гра- } \\
\text { вия в смеси, \% } \\
\text { Gravel content in } \\
\text { the mixture, \% }\end{array}$ & $\begin{array}{c}\text { Проницаемость, } \\
\text { мкм }^{2} \\
\text { Permeability, } \\
\text { mcm }^{2}\end{array}$ & $\begin{array}{l}K_{\text {смеси }} \\
K_{\text {песка }} \\
K_{\text {smesi }} \\
K_{\text {peska }}\end{array}$ \\
\hline \multirow{7}{*}{$0,25 \ldots 0,42$} & 0 & 11,1 & 1,0 & \multirow{7}{*}{$0,84 \ldots 2,0$} & 5 & 11,1 & 1,00 \\
\hline & 15 & 9,8 & 0,88 & & 15 & 12,7 & 1,02 \\
\hline & 25 & 10,2 & 0,92 & & 25 & 16,3 & 1,47 \\
\hline & 40 & 12,9 & 1,16 & & 40 & 12,8 & 1,15 \\
\hline & 50 & 17,2 & 1,55 & & 60 & 28,1 & 2,53 \\
\hline & 75 & 32,4 & 2,92 & & 75 & 67,0 & 6,04 \\
\hline & 100 & 69,0 & 6,22 & & 100 & $65, .0$ & 58,7 \\
\hline \multirow{6}{*}{$0,42 \ldots 0,84$} & 5 & 10,0 & 0,90 & \multirow{6}{*}{$2,0 \ldots 2,38$} & 5 & 12,1 & 1,09 \\
\hline & 15 & 10,0 & 0,90 & & 15 & 0,1 & 0,91 \\
\hline & 25 & 1,0 & 0,99 & & 25 & 14,3 & 1,29 \\
\hline & 40 & 15,3 & 1,38 & & 35 & 17,3 & 1,56 \\
\hline & 75 & 36,6 & 3,30 & & 50 & 14,0 & 1,26 \\
\hline & 100 & 170,8 & 15,4 & & 100 & 1969,9 & 177,3 \\
\hline
\end{tabular}

K-коэффиичент проницаемости/permeability coefficient.

Таблица 3. Значения проницаемости сжатых смесей

Table 3. Values of permeability of compressed mixtures

\begin{tabular}{|c|c|c|c|c|c|c|c|}
\hline $\begin{array}{c}\text { Размер } \\
\text { гравия, мм } \\
\text { Gravel size, } \\
\text { mm }\end{array}$ & $\begin{array}{l}\text { Содержание гравия } \\
\text { в смеси, \% } \\
\text { Gravel content in the } \\
\text { mixture, } \%\end{array}$ & $\begin{array}{c}\text { Проницаемость, } \\
\text { мкм }^{2} \\
\text { Permeability, } \\
\text { mcm }^{2}\end{array}$ & $\begin{array}{l}K_{\text {смеси }} \\
K_{\text {песка }} \\
K_{\text {smesi }} \\
K_{\text {peska }} \\
\end{array}$ & $\begin{array}{c}\text { Размер } \\
\text { гравия, мм } \\
\text { Gravel size, } \\
\text { mm }\end{array}$ & $\begin{array}{l}\text { Содержание гравия } \\
\text { в смеси, \% } \\
\text { Gravel content in the } \\
\text { mixture, } \%\end{array}$ & $\begin{array}{c}\text { Проницаемость, } \\
\text { мкм }^{2} \\
\text { Permeability, } \\
\text { mcm }^{2}\end{array}$ & $\begin{array}{l}K_{\text {смеси }} \\
K_{\text {песка }} \\
K_{\text {smesi }} \\
K_{\text {peska }}\end{array}$ \\
\hline \multirow{7}{*}{$0,25 \ldots 0,42$} & 0 & 8,74 & 1,0 & \multirow{7}{*}{$0,84 \ldots 2,0$} & 10 & 7,3 & 0,84 \\
\hline & 10 & 7,9 & 0,9 & & 25 & 4,5 & 0,51 \\
\hline & 15 & 7,7 & 0,88 & & 40 & 2,9 & 0,33 \\
\hline & 25 & 6,3 & 0,72 & & 100 & 517,4 & 59,2 \\
\hline & 50 & 7,1 & 0,81 & & - & - & - \\
\hline & 75 & 17,3 & 1,98 & & - & - & - \\
\hline & 100 & 69,7 & 7,97 & & - & - & - \\
\hline \multirow{5}{*}{$0,42 \ldots 0,84$} & 15 & 5,5 & 0,63 & \multirow{5}{*}{$2,0 \ldots 2,38$} & 10 & 7,4 & 0,85 \\
\hline & 40 & 3,5 & 0,40 & & 25 & 4,7 & 0,54 \\
\hline & 75 & 5,7 & 0,65 & & 40 & 3,0 & 0,34 \\
\hline & 100 & 120,7 & 13,81 & & 70 & 5,5 & 0,63 \\
\hline & - & - & - & & 100 & 2020,0 & 231,1 \\
\hline
\end{tabular}

Результаты экспериментальных работ по оценке способов снижения выноса песка из несцементированных неоднородных пластов показывают, что применение фильтров в обсаженном стволе требует создания гравийной набивки в кольцевом зазоре между фильтром и колонной, в перфорированном канале и за обсадной колонной. Причем размер гравия должен быть выбран таким, чтобы исключить перемешивание гравийной обсыпки с пластовым песком за счет миграции и интрузии песка, т. е. $D / d=4-5$. Снижения производительности скважин можно в этом случае избежать путем увеличения размера и количества перфорационных отверстий [26].

При постановке фильтров в открытом стволе значительную роль играют потери давления на поверхности раздела гравия с пластом, и следует отметить, что наибольшая производительность и эффективность фильтра в открытом стволе достигаются тогда, когда вокруг него имеется набивка, которую можно создать подрушением песчаного массива пласта путем циклического изменения дебита [27].

При выборе конструкции фильтра, одновременно с возможностью обеспечения им надежной гидравли- ческой связи в системе пласт-фильтр, решается и основная задача - предотвращение выноса песка в скважину. Следует отметить, что предотвращение выноса песка означает, что при оптимальном установившемся режиме работы скважины фильтр удерживает частицы скелета пласта, но пропускает мелкодисперсные и глинистые частицы.

В период запуска скважины картина несколько иная - пропускается и часть скелетообразующих частиц до того момента, пока на фильтрующей оболочке не образуется естественный фильтр из отсортированных крупных фракций. От количества и размера вынесенных частиц в большей степени зависит фор-

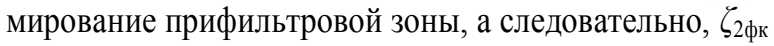
и $\zeta_{2 n}$.

Экспериментальные данные, полученные при определении оптимального способа снижения выноса песка из несцементированного илистого песчаного пласта с созданием естественной гравийной обсыпки из крупных фракций песка, показывают, что лучшие результаты получены при размере меньшей щели, рассчитанной на первоначальный пропуск 95 \% мел- 
ких фракций $\delta=d_{95}[28,29]$. Следует отметить, что эти данные приведены для трехслойного проволочнокаркасного фильтра фирмы «Джонсон», у которого размеры щели уменьшаются от наружного слоя к внутреннему в отношениях 3:2:1. Снижения выноса песка из слабосцементированного пласта на Анастасиевско-Троицком месторождении удалось добиться применением двухслойных проволочно-каркасных фильтров конструкции НПО «Термнефть». Размер щели принимался: на наружном слое фильтрующей оболочки раскрытостью 0,25 мм, равным или больше диаметра зерен песка в 95 \% точке по интегральной кривой гранулометрического состава $\left(\delta_{\text {нор }}=d_{95}\right)$, а на внутреннем - 0,15 мм. Внутренний зазор больше диаметра зерен песка в 50 \% точке, но меньше половины диаметра зерен в $85 \%$ точке интегральной кривой $\left(d_{50}<\delta_{\text {внутр }}<d_{85}\right)[30]$.

\section{СПИСОК ЛИТЕРАТУРЫ}

1. Игошин Д.Е., Никонова О.А., Мостовой П.Я. Моделирование пористой среды регулярными упаковками пересекающихся сфер // Вестник Тюменского государственного университета. - 2014. - № 7. - С. 34-42.

2. Исаева А.В., Доброжанский В.А. Математическое моделирование неизотермического фильтрационного течения в нефтяных пластах // Ломоносовские чтения. Секция физики. Сборник тезисов докладов. - М.: Физический факультет МГУ, 2017. - C. 240-242.

3. Kim Y.J., Lee K.H., Park C.Y. Limit loads for thin-walled piping branch junctions under combined pressure and in-plane bending // Journal of Strain Analysis for Engineering Design. - 2008. V. 43. - № 2. - P. 87-108.

4. Ватульян А.О., Нестеров С.А. Об одном способе идентификации термоупругих характеристик для неоднородных тел // Инженерно-физический журнал. - 2014. - Т. 87. - № 1. C. 217-224.

5. Брагин Ю.И., Вагин С.Б., Чоловский И.П. Нефтегазопромысловая геология и гидрогеология залежей углеводородов Справочник. - М.: Недра, 2004. - 400 с.

6. Юркив Н.И. Физико-химические основы нефтеизвлечения. М.: ОАО «ВНИИОЭНГ», 2005. - 366 с.

7. Коннов Ю.Д., Сидоркин Д.И., Хабибуллин М.Я. Механизация технологического процесса спускоподъемных операций при текущем и капитальном ремонте скважин // SOCAR Proceedings. - 2018. - № 2. - C. 15-24. DOI: 10.5510/OGP20180200346

8. Хабибуллин М.Я. Метод термокислотного импульсирования для увеличения нефтеотдачи // Нефтегазовое дело. - 2020. T. 18. - № 4. - C. 58-64. DOI: 10.17122/ngdelo-2020-4-58-64.

9. Хабибуллин М.Я. Совершенствование процесса солянокислотной обработки скважин применением новейших технологий и оборудования // Известия Томского политехнического университета. Инжиниринг георесурсов. - 2020. - Т. 331. № 10. - C. 128-134.

10. Dubinsky G.S. On the response of fractal structures of fluidsaturated reservoir rocks under wave impact // The Collection of Scientific Papers. The Development of Science in the 21st Century: Natural and Technical Sciences. - New York: Ron Bee \& Associates, 2015. - P. 51-56.

11. Гилаев Ген.Г., Хабибуллин М.Я., Гилаев Г.Г. Перспективы применения кислотного геля для закачки проппанта в процессе проведения гидроразрыва карбонатных пластов на территории самарской области // Нефтяное хозяйство. - 2020. № 8. - C. 54-57. DOI: 10.24887/0028-2448-2020-8-54-57.

12. Khabibullin M.Ya. Managing the processes accompanying fluid motion inside oil field converging-diverging pipes // Journal of Physics: Conference Series. International Conference «Information Technologies in Business and Industry». - 2019. - P. 042012. DOI: $10.1088 / 1742-6596 / 1333 / 4 / 042012$.

\section{Заключение}

Наиболее эффективными средствами предотвращения разрушения пласта являются титановые фильтры и гравийные набивки. Однако отмеченные недостатки сдерживают широкое их применение на промыслах страны. Также нет надежных средств предотвращения поступления песка в скважину из пласта с высокими значениями пластовой температуры, вязкости нефти, обводненности продукции. Частицы, которые составляют структуру породы, не должны выносится из пласта за счет применения фильтра. Практически это означает, что фильтр должен не пропускать 75-85 \% (по весу) более крупных фракций песка. Для сохранения общей устойчивости скелета пласта можно допустить вынос мелких частиц не более 15-25\% (во весу).

13. Khabibullin M.Ya. Managing the reliability of the tubing string in impulse non-stationary flooding // Journal of Physics: Conference Series. International Conference «Information Technologies in Business and Industry». 4. Mechatronics, Robotics and Electrical Drives. - 2019. - P. 052012. DOI: 10.1088/17426596/1333/5/052012.

14. Оценка коэффициентов извлечения нефти для месторождений Пермского края на основе статистических моделей / С.В. Галкин, Т.Б. Поплаухина, А.В. Распопов, Г.П. Хижняк // Нефтяное хозяйство. - 2009. - № 4. - С. 38-39.

15. Terentiev A.G. Deep water technology: problems and solutions // World Maritime Technology Conf. - St-Petersburg, 2012. - P. 1-7.

16. Jiabin Luo, Yongga Meng, Tianmin Shao. Research on mechanism of casing wear in sliding-impact wear condition // Advanced Tribology: Proceedings of CIST. - 2008. - P. 980-984.

17. Gao Deli, Sun Lianzhong, Lian Jihons. Prediction of casing wear in extended reach drilling // Petroleum Sience. - 2010. - № 7. P. 494-501.

18. Garkasi Ali Y., Yanghua Xiang, Gefri Lui. Casing wear in extended reach and multilateral wells // World Oil. - 2010. № 6. - P. 135-140.

19. Привалихин Р.С. Напряженное состояние в зоне контакта двух цилиндрических тел конечной длины // Общие проблемы машиностроения. - Красноярск: СФУ, 2011. - С. 599-603.

20. Климов В.В. Интерпретация данных профилеметрии обсадных колонн. Точность и инструментальная преемственность для скважин произвольного профиля // Oil\&Gas Journal Russia. - 2014. - № 5 (83). - C. 36-39.

21. Каменев П.А., Богомолов Л.М. О распределении по глубине коэффициента внутреннего трения и сцепления в массивах осадочных пород о. Сахалин // Геофизические исследования. 2017. - T. 18. - № 1. - C. 5-19.

22. Behnia M., Seifabad M.C. Stability analysis and optimization of the support system of an underground powerhouse cavern considering rock mass variability // Environmental Earth Sciences. - 2018. - V. 77. - № 18. - P. 354-362.

23. Lu H., Kim E., Gutierrez M. Monte Carlo simulation (MCS)-based uncertainty analysis of rock mass quality $Q$ in underground construction // Tunneling and Underground Space Technology. 2019. - V. 94. - № 5. - P. 278-284.

24. Cai M. Rock mass characterization and rock property variability considerations for tunnel and cavern design // Rock Mechanics and Rock Engineering. - 2011. - V. 44. - № 4. - P. 379-399.

25. A probabilistic assessment of the casing integrity in a Pre-salt wellbore / P.A.L.P. Firme, F.L.G. Pereira, D. Roehl, C. Romanel // 50th US Rock Mechanics Geomechanics Symposium. - USA, Houston, 2016. - V. 3. - P. 2555-2564

26. Aregbe A.G. Wellbore stability problems in deepwater gas wells // World Journal of Engineering and Technology. - 2017. - V. 05. № 04. - P. 626-647.

27. Zhang J., Lu Y. Study on temperature distribution of ultra-deep wellbore and its effect on mechanical properties of surrounding 
rock // Chinese Journal of Rock Mechanics and Engineering. 2019. - V. 38. - P. 2831-2839.

28. Manshad A., Jalalifar H., Aslannejad M. Analysis of vertical, horizontal and deviated wellbores stability by analytical and numerical methods // Journal of Petroleum Exploration and Production Technology. - 2014. - V. 4. - P. 359-369.

29. Gaede O., Karrech A., Regenauer-Lieb K. Anisotropic damage mechanics as a novel approach to improve pre- and post-failure borehole stability analysis // Geophysical Journal International. 2013. - V. 193. - № 3. - P. 1095-1109.

30. A wellbore stability model for formations with anisotropic rock strengths / H. Lee, S.H. Ong, M. Azeemuddin, H. Goodman // Journal of Petroleum Science and Engineering. - 2012. - V. 96-97. P. 109-119.

Поступила 22.09.2021 2.

\section{Информация об авторах}

Хабибуллин М.Я., кандидат технических наук, доцент кафедры нефтепромысловых машин и оборудования, Уфимский государственный нефтяной технический университет, филиал в г. Октябрьский. 
UDC 622.322

\title{
MECHANISM OF FILTRATION OF FORMATION LIQUID IN A FILTER IN CONTACT WITH ROCK
}

\author{
Marat Ya. Khabibullin, \\ m-hab@mail.ru \\ Ufa State Petroleum Technological University, branch in Oktyabrsky, \\ 54-a, Devonskaya avenue, Oktyabrsky, 452607, Russia.
}

\begin{abstract}
The relevance of the study is caused by the need to prevent the introduction of a volume of rock with greater homogeneity and larger size into the near-filter zone compared to the coarse fraction of formation sand - an attempt to improve the filtration properties of the near-filter zone, i. e. decrease in $\zeta_{2 \phi k}$ and $\zeta_{2 n}$. The design of the gravel pack should simultaneously exclude the removal of formation particles into the well. The solution to this problem will improve the work of filtration of formation fluid from the formation into the well and reduce the cost of additional application of methods for stimulating the inflow of formation fluid to the well.
\end{abstract}

Purpose: to develop a methodology that allows, when choosing a filter design, simultaneously with the ability to provide them with a reliable hydraulic connection in the reservoir-filter system, preventing sand removal into the well.

Objects. To prevent the flow of sand from the formation and retain gravel at the bottom of the well, when creating gravel packs, slot, wire, ring, titanium, cermet and other filters are used. These screens, installed in the casing perforation interval without the formation of gravel outer annular packing (and this is how screens are installed in most wells in Russian fields), are very often clogged with formation sand, which leads to a decrease in well productivity. If slot filters are used to retain sand, then the effectiveness of their application depends on the correspondence of the slot size to the granulometric composition of the sand being removed. Filters with shell packing are more effective, but they also do not always meet the set goal, since the strength and quality of shell rock pumped into the near-wellbore part of the formation are rather low. In addition, wire filters used in the fields do not have fixation of each turn, as a result of which, if one of the turns is mechanically damaged, the entire winding breaks down.

Methods. When applying the proposed technique, the results of experimental work on evaluating ways to reduce sand production from unconsolidated heterogeneous formations show that the use of filters in a cased hole requires the creation of gravel packing in the annular gap between the filter and the string, in the perforated channel and behind the casing. Moreover, the size of the gravel should be chosen so as to exclude the mixing of the gravel packing with the formation sand due to the migration and intrusion of sand, i.e. $D / d=4-5$. A decrease in well productivity can in this case be avoided by increasing the size and number of perforations. It should be noted that sand avoidance means that under optimal steady state well operation, the filter retains formation backbone particles, but allows fines and clay particles to pass through. During the well start-up, the picture is somewhat different - part of the skeletal particles is also passed through until a natural filter of sorted coarse fractions is formed on the filtering casing.

Results. The particles that make up the rock structure should not be carried out of the formation by applying a filter. In practice, this means that the filter should not pass 75-85\% (by weight) of the larger sand fractions. To maintain the overall stability of the formation skeleton, it is possible to allow the removal of small particles not more than $15-25 \%$ (in weight).

\section{Key words:}

Sandstone, borehole, well, thermal, methods, intensive.

\section{REFERENCE}

1. Igoshin D.E., Nikonova O.A., Mostovoy P.Ya. Modeling a porous medium by regular packings of intersecting spheres. Bulletin of the Tyumen State University, 2014, no. 7, pp. 34-42. In Rus.

2. Isaeva A.V., Dobrozhansky V.A. Matematicheskoe modelirovanie neizotermicheskogo filtratsionnogo techeniya $\mathrm{v}$ neftyanykh plastakh [Mathematical modeling of non-isothermal filtration flow in oil reservoirs]. Lomonosovskie chteniya. sektsiya fiziki. Sbornik tezisov dokladov [Lomonosov readings. Physics section. Collection of abstracts]. Moscow, Faculty of Physics, Moscow State University Publ., 2017. pp. 240-242.

3. Kim Y.J., Lee K.H., Park C.Y. Limit loads for thin-walled piping branch junctions under combined pressure and in-plane bending. Journal of Strain Analysis for Engineering Design, 2008, vol. 43, no. 2, pp. 87-108.

4. Vatulyan A.O., Nesterov S.A. On one method of identification of thermoelastic characteristics for inhomogeneous bodies. Inzhenernofizicheskii zhurnal, 2014, vol. 87, no. 1, pp. 217-224. In Rus.

5. Bragin Yu.I., Vagin S.B., Cholovsky I.P. Neftegazopromyslovaya geologiya i gidrogeologiva zalezhey uglevodorodov. Spravochnik [Oil and gas field geology and hydrogeology of hydrocarbon deposits. Reference]. Moscow, Nedra Publ., 2004. 400 p.

6. Yurkiv N.I. Fiziko-khimicheskie osnovy nefteizvlecheniya [Physicochemical foundations of oil recovery]. Moscow, VNIIOENG Publ., 2005. 366 p.

7. Konnov Yu.D., Sidorkin D.I., Khabibullin M.Ya. Mechanization of the technological process of round-trip operations during routine and overhaul of wells. SOCAR Proceedings, 2018, no. 2, pp. 15-24. In Rus. DOI: 10.5510 / OGP20180200346.

8. Khabibullin M. Ya. The method of thermoacid impulse to increase oil recovery. Oil and Gas Business, 2020, vol. 18, no. 4, pp. 58-64. In Rus. DOI: 10.17122 / ngdelo-2020-4-58-64.

9. Khabibullin M. Ya. Improving the process of hydrochloric acid treatment of wells using the latest technologies and equipment. Bulletin of the Tomsk Polytechnic University. Geo Assets Engineering, 2020, vol. 331, no. 10, pp. 128-134. In Rus.

10. Dubinsky G.S. On the response of fractal structures of fluidsaturated reservoir rocks under wave impact. The Collection of Scientific Papers. The Development of Science in the $21^{\text {st }}$ Century: Natural and Technical Sciences. New York, Ron Bee \& Associates, 2015. pp. 51-56.

11. Gilaev Gen.G., Khabibullin M.Ya., Gilaev G.G. Prospects for the use of acid gel for pumping proppant in the process of hydraulic fracturing of carbonate reservoirs in the Samara region. Oil industry, 2020, no. 8, pp. 54-57. In Rus. DOI: 10.24887 / 00282448-2020-8-54-57.

12. Khabibullin M.Ya. Managing the processes accompanying fluid motion inside oil field converging-diverging pipes. Journal of Physics: Conference Series. International Conference "Information Technologies in Business and Industry», 2019, pp. 042012. DOI: 10.1088/1742-6596/1333/4/042012.

13. Khabibullin M.Ya. Managing the reliability of the tubing string in impulse non-stationary flooding. Journal of Physics: Conference Series. International Conference "Information Technologies in Business and Industry». 4. Mechatronics, Robotics and Electrical 
Drives, 2019, pp. 052012.DOI: 10.1088/1742-6596/1333/5/ 052012 .

14. Galkin S.V., Poplaukhina T.B., Raspopov A.V., Khizhnyak G.P. Evaluation of oil recovery factors for the fields of the Perm Territory on the basis of statistical models. Oil Industry, 2009, no. 4, pp. 38-39. In Rus.

15. Terentiev A.G. Deep water technology: problems and solutions. World Maritime Technology Conf. Saint-Petersburg, 2012. pp. 1-7.

16. Jiabin Luo, Yongga Meng, Tianmin Shao. Research on Mechanism of Casing Wear in Sliding-Impact Wear Condition. Advanced Tribology: Proceedings of CIST, 2008, pp. 980-984.

17. Gao Deli, Sun Lianzhong, Lian Jihons. Prediction of casing wear in extended reach drilling. Petroleum Sconce, 2010, vol. 7, pp. 494-501.

18. Garkasi Ali Y., Yanghua Xiang, Gefri Lui. Casing wear in extended reach and multilateral wells. World Oil, 2010, no. 6, pp. 135-140.

19. Privalikhin R.S. Napryazhennoe sostoyanie v zone kontakta dvukh tsilindricheskikh tel konechnoy dliny [Stress state in the contact zone of two cylindrical bodies of finite length]. Obshchie problemy mashinostroeniya [General problems of mechanical engineering]. Krasnoyarsk, Siberian Federal University Publ., 2011. pp. 599-603.

20. Klimov V.V. Interpretation of casing profile data. Accuracy and instrumental continuity for wells of arbitrary profile. Oil \& Gas Journal Russia, 2014, no. 5 (83), pp. 36-39. In Rus.

21. Kamenev P.A., Bogomolov L.M. On the depth distribution of the coefficient of internal friction and cohesion in sedimentary rock massifs Sakhalin. Geophysical Research, 2017, vol. 18, no. 1, pp. 5-19. In Rus.

22. Behnia M., Seifabad M.C. Stability analysis and optimization of the support system of an underground powerhouse cavern considering rock mass variability. Environmental Earth Sciences, 2018, vol. 77, no. 18, pp. 354-362.
23. Lu H., Kim E., Gutierrez M. Monte Carlo simulation (MCS)-based uncertainty analysis of rock mass quality $\mathrm{Q}$ in underground construction. Tunneling and Underground Space Technology, 2019, vol. 94, no. 5, pp. 278-284

24. Cai M. Rock mass characterization and rock property variability considerations for tunnel and cavern design. Rock Mechanics and Rock Engineering, 2011, vol. 44, no. 4, pp. 379-399.

25. Firme P.A.L.P., Pereira F.L.G., Roehl D., Romanel C. A probabilistic assessment of the casing integrity in a Pre-salt wellbore. $50^{\text {th }}$ US Rock Mechanics Geomechanics Symposium. USA, Houston, 2016, vol. 3, pp. 2555-2564.

26. Aregbe A.G. Wellbore stability problems in deepwater gas wells. World Journal of Engineering and Technology, 2017,vol. 05, no. 04 , pp. $626-647$.

27. Zhang J., Lu Y. Study on temperature distribution of ultra-deep wellbore and its effect on mechanical properties of surrounding rock. Chinese Journal of Rock Mechanics and Engineering, 2019, vol. 38, pp. 2831-2839.

28. Manshad A., Jalalifar H., Aslannejad M. Analysis of vertical, horizontal and deviated wellbores stability by analytical and numerical methods. Journal of Petroleum Exploration and Production Technology, 2014, vol. 4, pp. 359-369.

29. Gaede O., Karrech A., Regenauer-Lieb K. Anisotropic damage mechanics as a novel approach to improve pre- and post-failure borehole stability analysis. Geophysical Journal International, 2013, vol. 193, no. 3, pp. 1095-1109.

30. Lee H., Ong S.H., Azeemuddin M., Goodman H. A wellbore stability model for formations with anisotropic rock strengths. Journal of Petroleum Science and Engineering, 2012, vol. 96-97, pp. 109-119.

Received: 22 September 2021.

\section{Information about the authors}

Marat Ya. Khabibullin, Cand. Sc., associate professor, Ufa State Petroleum Technological University, branch in Oktyabrsky. 